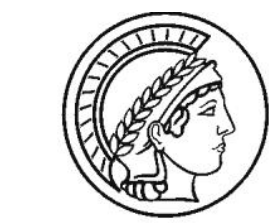

$\overline{\text { MAX-PLANCK-GESELLSCHAFT }}$

15. Conference of GDCh Division for Solid State Chemistry and Material Research

Berlin (Germany), 20.09.-22.09.2010

\title{
In situ Neutron Diffraction Study of a Methanol Synthesis Catalyst under Working Conditions
}

\author{
Timur Kandemir ${ }^{\text {[a] }}$ Dirk Wallacher, ${ }^{[b]}$ \\ Michael Tovar, ${ }^{[\mathrm{b}]}$ and Malte Behrens ${ }^{\mid[\mathrm{a}]}$
}

Keywords: Neutron diffraction; Heterogenous catalysis

A reactor setup for the in siti study of methanol synthesis catalysts using neutron diffraction (ND) was designed, which allows investigation of structural and microstructural features of Cu-based catalysts [ 1] under demanding reaction conditions like elevated pressure and temperature (up to $250^{\circ} \mathrm{C}$ and 60 bars). The evolution of phase composition, crystallite size, lattice strain and defect density during the catalytic reaction is probed in siltu with ND data (Fig. 1) acquired using the Fine Resolution Powder Diffractometer (FIREPOD) at the BER2 research reactor of the Helmholtz Centre Berlin [2]

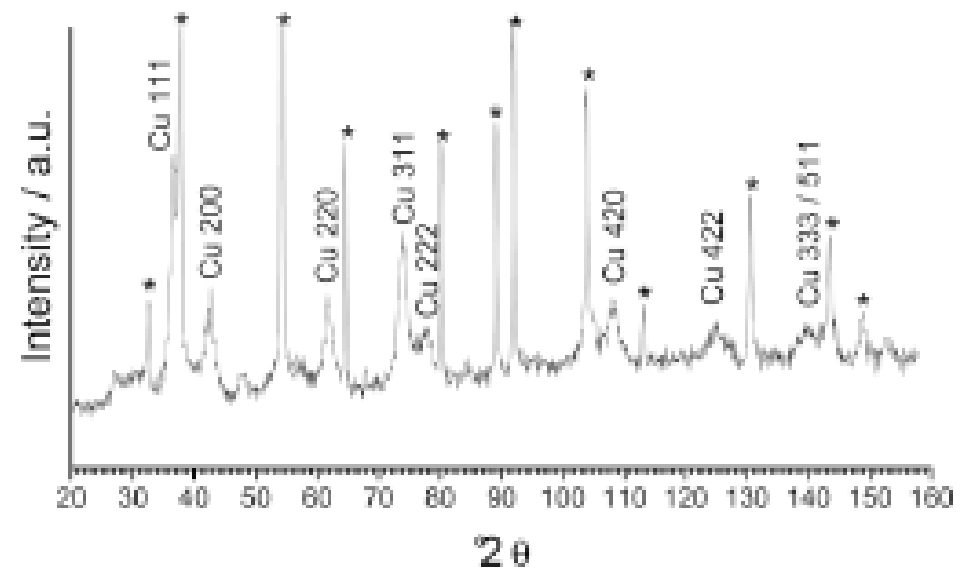

Figure 1. ND pattern of a $\mathrm{Cu} / \mathrm{ZnO} / \mathrm{Al}_{2} \mathrm{O}_{3}$ catalyst in 50 bar $\mathrm{D}_{2}$ at $250^{\circ} \mathrm{C}$. Sharp reflections " $" * "$ are due to $\mathrm{Al}$ reactor.

[1] L. Kasatbin, P. Kurr, B. Kriep, A. Trunschle, R. Schlög1, Angew. Chem. In Ed, 2007, 46732473327.

[2] R. Michaeken, Nesbon News 2001, 127-9. 